\title{
Características das situações estressantes em gestores universitários no contexto do trabalho
}

\section{Characteristics of stressful situations in university managers in the context of work}

\author{
Fernanda Ax Wilhelm* \\ Universidade Federal de Roraima - UFRR, Boa Vista, Roraima, Brasil
}

\section{J osé Carlos Zanelli**}

Universidade Federal de Santa Catarina - UFSC, Florianópolis, Santa Catarina, Brasil.

\begin{abstract}
RESUMO
O estresse constitui um fenômeno complexo que necessita ser compreendido por meio de diferentes contextos. É considerado positivo e necessário para a sobrevivência, e negativo quando sua exposição ocorre de maneira constante e incontrolável. O objetivo deste estudo foi analisar as situações estressantes vivenciadas por vinte e um gestores pertencentes a duas universidades públicas do Sul do País. Foi utilizado um roteiro de entrevista com perguntas semi-estruturadas. A análise dos dados foi feita por meio da construção de categorias, a partir das verbalizações dos participantes. Os gestores indicaram vivenciar situações estressantes, demonstrando ser o estresse uma condição inevitável. Essas situações foram relacionadas a lidar com pessoas; alta demanda de trabalho; processos burocráticos; características pessoais, entre outras. Nessas Universidades não há preparação para ser gestor. Os gestores indicaram a aquisição de experiência profissional durante o exercício do cargo de gestão e em cargos anteriores. Analisaram que maturidade e tempo de serviço também auxiliam no exercício da função.
\end{abstract}

Palavras-chave: Estresse, Gestão, Universidade.

\section{ABSTRACT}

Stress is a complex phenomenon that needs to be understood in different contexts. It is considered positive and necessary for survival and negative when its exposure occurs constantly and uncontrollably. The goal of this study was to analyze the stressful situations experienced by twenty-one managers who work in two public universities in the south of the country. It was used an interview guide with questions semi-structured. The analysis of the data was done through the construction of categories from the participants' verbalizations. The managers indicated that they live stressful situations demonstrating that the stress is an unavoidable condition. It was related to dealing with people, high job demands, bureaucratic processes, personal characteristics, among others. These universities there is no preparation to be a manager. The managers indicated the acquisition of professional experience while they were doing it in previous positions of 
managing. They analyzed that the maturity and time service may also help to exercise the function.

Keywords: Stress, Management, University.

\section{I ntrodução}

\subsection{Caracterização do estresse}

O estresse é uma condição inevitável da vida humana (SELYE, 1959; PAZ, 2008), pois os agentes estressores estão presentes em todas as atividades laborais (BENEVIDES-PEREIRA; DAVID; BLASCO, 2005). Inerente, necessário e positivo ao contexto de trabalho em níveis mínimos (TAMAYO, 2008), o "estresse" é definido nesse estudo como "uma reação muito complexa, composta de alterações psicofisiológicas que ocorrem quando o indivíduo é forçado a enfrentar situações que ultrapassem sua habilidade de enfrentamento" (LIPP; TANGANELLI, 2002, p. 138). Essas situações são avaliadas como sobrecarga que excede os recursos atuais, físicos e/ou psíquicos para cumprir tais exigências (PAZ, 2008; VASCONCELOS; VASCONCELOS; CRUBELLATE, 2008).

$O$ estresse no local de trabalho, quando sua exposição ocorre de maneira constante e incontrolável, pode resultar em custos elevados para os indivíduos, as organizações e a sociedade (SADIR; LIPP, 2009; BALASSIANO; TAVARES; PIMENTA, 2011). O estresse ocupacional, presente em qualquer profissão ou nível hierárquico, pode ser definido como um processo em que o indivíduo percebe demandas do trabalho como estressoras. É responsabilidade do gestor estar capacitado para gerir e reduzir o próprio estresse e para auxiliar na diminuição das condições de estresse de seus subordinados (BALASSIANO; TAVARES; PIMENTA, 2011). Assim, é relevante conhecer melhor as variáveis estressoras que interferem nas condições de trabalho das pessoas em seus contextos de trabalho, em especial, neste estudo, os Gestores Universitários.

$O$ estresse pode ser considerado positivo ou negativo (BENEVIDESPEREIRA; DAVID; BLASCO, 2005; TAMAYO, 2008). É positivo quando mantém a produtividade e o desempenho, produz energia para lidar com as situações, realizar tarefas e mobilizar recursos pessoais para lidar com as demandas do ambiente (SILVA; MARTINEZ, 2005; ASSMAR; FERREIRA, 2008). É considerado saudável e necessário para a sobrevivência do indivíduo quando em níveis mínimos, na adaptação às exigências do meio externo ou, ainda, para que as pessoas possam responder a metas e desafios que fixam para si próprias e que ocorrem nas diversas áreas, como por exemplo, no trabalho, na prática de esportes e em atividades de aventura. Portanto, nessas situações, é considerado como resultado natural das 
condições vivenciadas na sociedade moderna (VASCONCELOS et al., 2008).

Em contrapartida, o estresse é considerado negativo quando ocorre de maneira constante, excessiva e incontrolável, gerando pressão e desequilíbrio (LIPP, 2005; SILVA; MARTINEZ, 2005; TAMAYO, 2008), por exigências do ambiente que excedem os recursos pessoais do indivíduo (BENZONI, 2008). Em excesso, interfere na qualidade de vida ao modificar a maneira como o indivíduo interage na área social, afetiva, profissional e de saúde (LIPP; TANGANELLI, 2002; ZANELLI et al., 2010). Os aspectos que diferenciam basicamente o estresse positivo do negativo residem na intensidade, frequência e duração da exposição e, ainda, na falta de controle sobre a situação estressante (TAMAYO, 2008). De modo geral, um estado prolongado de estresse pode interferir na saúde, no bem-estar físico e psicológico e na qualidade de vida das pessoas (LIPP; TANGANELLI, 2002; LIPP, 2005; MORALES, 2006; FERREIRA; ASSMAR, 2008; ZANELLI et al., 2010). Em excesso, tem sido considerado um dos principais problemas do mundo moderno, dadas as suas consequências (VASCONCELOS; VASCONCELOS; CRUBELLATE, 2008).

$O$ estresse é um fenômeno complexo, e seus efeitos podem ser específicos em cada sujeito. Ao considerar que fenômenos como o estresse podem afetar de diferentes formas o trabalho dos gestores no cotidiano das organizações, considera-se a importância de conhecer os fatores que levam as pessoas a lidar com situações estressantes em seus contextos de trabalho. Assim, levando em conta que a atuação nas universidades requer gestores com habilidades para lidar com situações de estresse no cotidiano, de modo a manter condições de bem-estar e amenizar os efeitos dessas situações, diante de um contexto de mudanças e exigências contínuas, este estudo pretendeu produzir, especialmente para o contexto universitário, conhecimento que permita responder ao objetivo: analisar as situações estressantes vivenciadas por gestores universitários no contexto de trabalho.

\subsection{Gestão universitária em um contexto de exigências e desafios}

São constantes os desafios e processos de mudanças impostos às universidades. Atualmente, inseridas em um contexto altamente competitivo, elas enfrentam desafios como as mudanças provocadas pelos avanços tecnológicos, expectativas relacionadas ao ensino superior, aspectos referentes à competitividade e à complexidade das organizações, a crescente busca por resultados, por excelência operacional, além de seu papel no desenvolvimento das sociedades e economias exigir dos gestores uma atuação diferenciada (ÉSTHER, 2007; CRUZ, 2008). Essas mudanças impõem às universidades 
respostas rápidas a esses desafios e necessidade de reestruturação de suas organizações, reordenamento de suas posições e atuações no mercado. As novas exigências estão associadas a fatores relacionados à melhoria constante na qualidade de ensino, à escassez de recursos, ao aumento do controle externo (por exemplo, o exame nacional de desempenho estudantil e a avaliação institucional) e da concorrência, à diversidade discente, à introdução de novas tecnologias, às mudanças no sentido social atribuído às universidades, como a demanda e discussão da autonomia universitária, entre outros (KANAN, 2008).

Considerando o contexto dinâmico e complexo das universidades, quais são as funções inerentes ao gestor universitário? A principal função dos que ocupam cargos de chefia é a de tomar decisões para obter resultados. Nas organizações, em geral, os gestores enfrentam dilemas ao decidir o que fazer, apesar da incerteza, e ao lidar com a diversidade e o volume de informações relevantes (BENEVIDESPEREIRA et al., 2005). Estas são características importantes no exercício do cargo de gestor universitário: ter visão de futuro, domínio da tecnologia, visão estratégica, capacidade de decisão; gerenciar informações; ser empreendedor e participativo. Também são considerados aspectos referentes a particularidades, realidade, tamanho, tipo ou natureza e cultura organizacional das universidades (ÉSTHER, 2007; KANAN, 2008). Ser gestor envolve, ainda, as dimensões administrativa, pedagógica, científica, econômica e gerencial, e a responsabilidade pelo trabalho e por pessoas (KANAN; ZANELLI, 2011).

Estudos sobre a função gerencial de docentes de universidades brasileiras públicas e privadas demonstram que suas funções estão diluídas em práticas sociais e que suas atividades muitas vezes são caracterizadas por indefinições, imediatismo, falta de planejamento e improvisação (MARRA; MELO, 2005). Contínuas revisões das estruturas universitárias e a aprendizagem de comportamentos de gestão são relevantes, uma vez que o exercício de tal função não segue ações padronizadas nem se prende a normas e rotinas. Outro aspecto diz respeito à precariedade de detalhamento e organização das atribuições inerentes ao cargo de gestor, que tem implicações diversas sobre o que os dirigentes precisam fazer ou sobre as atividades de sua responsabilidade (CRUZ, 2008). Ocorre a falta de conhecimentos específicos para a área de gestão bem como em relação às questões administrativas inerentes ao cargo. Portanto, não é comum nas universidades a prática de investir em capacitação para profissionais que ocupam funções gerenciais. Mas a aprendizagem gerencial pode ocorrer de modo formal e informal, no caso dos gestores universitários, por meio de suas experiências e trajetórias de trabalho (KANAN; ZANELLI, 2011). 
É comum professores universitários ocuparem cargos de Direção, muitas vezes enfrentando situações e assumindo responsabilidades para as quais não foram preparados. Concluindo seu mandato gerencial, os ex-gestores retornam às atividades docentes e de pesquisa. Outra característica diz respeito ao tempo, que é determinado. A troca periódica de dirigentes ocasiona uma descontinuidade gerencial, e nem sempre os diretores têm total autonomia no exercício de suas práticas administrativas. As constantes decisões na rotina de trabalho muitas vezes são tomadas em conjunto com colegiados (MARRA; MELO, 2005; ÉSTHER, 2007; CRUZ, 2008).

\section{Método}

\subsection{Participantes da pesquisa}

Foram participantes quatro gestores que atuavam, por ocasião das entrevistas para a coleta de dados, no cargo de pró-reitor em uma universidade pública do Sul do País. Também foram participantes dezessete gestores que atuavam em outra universidade pública nos cargos de pró-reitor, diretor de centro e secretário especial (que detém status de pró-reitor). O critério estabelecido para seleção dos participantes foi 'estar no exercício dessas funções no período mínimo de um ano', supondo-se que nesse período as características do fenômeno investigado estariam presentes.

\subsection{Instrumentos, fontes de informação e equipamento utilizado}

Foi utilizado como instrumento um roteiro de entrevista com perguntas semiestruturadas e, em um segundo momento, um roteiro com perguntas de aplicação recorrente, com base nas respostas fornecidas pelos participantes na entrevista. $O$ equipamento utilizado para registro das respostas foi um gravador.

\subsection{Contatos com os participantes e aplicação dos instrumentos}

Foram empregadas diferentes estratégias para ter acesso aos participantes: e-mails, auxílio de pessoas que trabalhavam na universidade, auxílio do vice-reitor, contato por telefone e ida pessoalmente aos locais de trabalho de cada gestor. Os procedimentos foram realizados individualmente, nas salas dos gestores, conforme disponibilidade destes. O local foi considerado apropriado por apresentar as seguintes características: sem fluxo de 
pessoas nem ruídos para evitar interrupções e interferências, iluminação satisfatória e ambiente ventilado.

Inicialmente, foram dadas explicações preliminares e esclarecimentos de possíveis dúvidas; em seguida, foi realizada a aplicação do roteiro de entrevista para conhecer com maior aprofundamento as situações estressantes vivenciadas por gestores universitários com questões relacionadas a estas categorias: dados demográficos, atuação profissional na universidade e características sobre estresse e gestão universitária. Em muitos casos, as entrevistas foram desmarcadas várias vezes ocasionando atraso na etapa de coleta de dados.

Foi lido e entregue o Termo de Consentimento Livre e Esclarecido (TCLE). Foram apresentadas informações gerais em relação ao objetivo da pesquisa, ao sigilo e anonimato dos participantes e à organização em que atuam. As entrevistas foram gravadas e posteriormente transcritas.

\subsection{Recorrência}

A recorrência tem por objetivo retornar aos participantes para complementar as informações fornecidas. Estas são posteriormente checadas pelos próprios participantes, permitindo-lhes modificar, alterar, corrigir, acrescentar ou suprimir conteúdos, em favor do real significado de suas palavras. A cada nova mudança solicitada pelo participante, é realizada uma nova checagem das inferências até que ele as aprove. As recorrências podem, ainda, ser utilizadas com a intenção de sistematizar os conteúdos em matrizes de relações. Desta forma, as informações contidas nas matrizes se transformam em dados, constituindo matrizes teóricas individuais elaboradas a partir do conteúdo das entrevistas (ZANELLI, 2002; KANAN; ZANELLI, 2011).

Foi feito contato telefônico com os gestores para agendar o procedimento de recorrência. Esta etapa apresentou como objetivo responder questões de modo a complementar, tirar dúvidas e aprofundar alguns aspectos da entrevista realizada anteriormente. Em função do tempo disponível, foi feita a leitura das situações estressantes relatadas pelos participantes na entrevista. Nesse momento, os gestores tiveram a oportunidade de corrigir e acrescentar mais informações caso considerassem necessário fazê-lo.

\section{Resultados}

\subsection{Breve caracterização das organizações universitárias}

Segundo informações obtidas nos sites das duas universidades (dados de 2011), ambas foram fundadas na década de 1960. A 
primeira Universidade possui aproximadamente 1.052 professores, 458 servidores administrativos, 4.253 alunos de graduação e 566 alunos de pós-graduação, com uma população aproximada de 6.329 pessoas. Na segunda Universidade, os gestores compõem uma população aproximada de 35.879 pessoas, com 20.740 alunos de graduação, 7.982 alunos de pós-graduação, 1.779 docentes e 2.783 servidores administrativos.

\subsection{Caracterização geral dos gestores universitários}

Dos vinte e um gestores participantes, quatorze eram homens e sete mulheres. Em relação aos cargos, onze gestores eram diretores de centro, dos quais sete homens e quatro mulheres. Foram identificados sete como pró-reitores, dos quais cinco homens e duas mulheres. Em relação aos secretários especiais, participaram dois homens e uma mulher.

Os gestores foram identificados pelas nomeações de G1 a G21. Os gestores nomeados como G1 a G4 são da primeira universidade estudada; os nomeados como G5 a G21 são da segunda. Sobre o tempo de atuação nas respectivas instituições, dez gestores têm mais de trinta anos na universidade (entre 30 e 36). G14, por exemplo, que tem 36 anos de atuação, sempre ocupou cargos de gestão em sua trajetória profissional e assume a Reitoria quando o reitor e 0 vice-reitor estão ausentes. Oito gestores têm atuação de até 20 anos (6 a 16 anos); três têm entre 20 e 30 anos de atuação.

Em relação ao estado civil, quatorze participantes eram casados, cinco eram divorciados, e dois, solteiros. Quanto à idade, onze gestores tinham, por ocasião da pesquisa, entre 50 e 60 anos; sete, entre 44 e 55 anos; três tinham acima dos 60 anos. Quanto ao número de filhos, a maioria dos gestores tinham dois filhos e uma gestora não tinha filhos na época da pesquisa. Quatro têm filhos com idade inferior a dez anos. Dezessete gestores, além da atividade de gestão, estão envolvidos com atividades relacionadas à pósgraduação, graduação e pesquisa (lecionar disciplinas e orientar pesquisas), e, destes, dois exercem também atividades de extensão. Um gestor exerce apenas atividades relacionadas à orientação de pesquisa, e outro participa de um grupo de pesquisa. Dois participantes não exercem outras atividades além da gestão.

Os gestores têm, em sua maioria, titulação em nível de doutorado. Entre os que exercem outras atividades, doze relataram ter reduzido um pouco as atividades de trabalho, um gestor relatou ter reduzido bastante e um relatou não ter reduzido suas atividades quando assumiu o cargo de gestor. Todos os gestores já assumiram atividades de gestão na universidade anteriormente. Os cargos mais citados foram estes: coordenador de curso, chefe de departamento, coordenador de pós-graduação, diretor de centro e vice-diretor. Dois 
gestores relataram ter assumido cargos de gestão fora da universidade, como de secretário estadual ou municipal de educação e diretor de banco.

\section{Discussão e análise}

\subsection{Tipos de situações estressantes vivenciadas por gestores universitários no contexto de trabalho}

Todos os gestores relataram vivenciar mais de uma situação estressante em seu contexto de trabalho. Esse aspecto evidencia que o estresse está presente na vida das pessoas, sendo uma condição inevitável da vida humana (SELYE, 1959; PAZ, 2008). Essas situações foram agrupadas nas categorias a seguir. Primeiramente relacionam-se as categorias mais citadas.

\subsubsection{Lidar com pessoas}

Foram indicadas pelos participantes da pesquisa, as seguintes situações estressantes relacionadas com a categoria "lidar com pessoas": falta de habilidade na gestão de pessoas; entender determinadas críticas como um ataque pessoal e não um problema político; vaidade das pessoas; interesses individuais e não coletivos; tratar questões públicas como pessoais; demanda intensa por reconhecimento; pessoas estanques e inflexíveis nas suas posições; encaminhamento de e-mails de trabalho com respostas agressivas; não cumprimento de prazos e responsabilidades; pessoas que procuram o gestor sem agendar com antecedência, atrasando a programação do dia; cultura da não mudança, relatada por G8 e representada por falas de pessoas em geral na segunda Universidade estudada que afirmam: "só falta dez anos pra me aposentar"; fofocas; má fé; pessoas que cobram a resolução de seus problemas rapidamente; brigas internas, dentro do departamento; pessoas que chegam à Direção gritando exaltadas; pessoas com sentimento de cansaço e desvalorização; e ausência de um trabalho mais democrático e participativo.

Essa categoria foi a mais citada entre os gestores universitários. Conforme fala de dois participantes (G17 e G21), o trabalho de gestão diz respeito a "lidar com diferentes categorias como aluno, professor, [servidor] técnico administrativo, comunidade". Entre as dimensões que envolvem o trabalho de um gestor, está a responsabilidade pelo trabalho, mas também pelas pessoas, que requisitam habilidades relacionais e pessoais (KANAN; ZANELLI, 2011), como pode ser constatado na fala de G18: “a Universidade é toda feita por pessoas [...]. Não tem como administrar só com 
papéis. Tem a parte pessoal importantíssima para poder fazer as coisas funcionarem". É possível destacar que trabalhar com pessoas constitui um desafio para qualquer organização, especialmente nas organizações públicas, em que as decisões são colegiadas e emanadas por pessoas com diferentes formações, interesses e valores que interferem nos processos decisórios.

\subsubsection{Processos burocráticos/ outros setores}

Essa categoria foi caracterizada pelas seguintes situações causadoras de estresse: reuniões longas; excesso de reuniões; reuniões sem objetividade e não produtivas; pessoas que não demonstram seus posicionamentos nas reuniões, como pode ser exemplificado na fala de G4: "Excesso de reuniões que são longas e sem objetividade; eu não tenho vontade de acordar de manhã para vir para reunião [...] 0 que já cheguei atrasado nessa reunião [...]"; responder a processos e relatórios diversos; realizar licitações diversas que exigem tempo e recursos financeiros; prestação de contas; falta de planejamento; encaminhamento de outros setores muitas vezes com erros; encaminhamento de solicitações que, por vezes, não são respondidas nem atendidas, segundo pode ser verificado na fala de G11: "eu gosto de trabalhar. O trabalho não me assusta [...] a gente trabalha e trabalha e aí todo o teu trabalho pode ir por água abaixo porque alguém lá não fez o que deveria ser feito".

Situações como falta de planejamento, solicitações que não são respondidas nem atendidas, encaminhamentos de outros setores com erros podem evidenciar atividades estressoras nas universidades muitas vezes caracterizadas por indefinições e improvisação, com a ausência de ações padronizadas (CRUZ, 2008).

\subsubsection{Atividades da graduação e pós-graduação}

Os gestores indicaram como originárias de estresse nessa categoria, as seguintes situações: elaborar e corrigir provas; preparar e ministrar aulas; cobranças por produção científica (currículo lattes); participar como membro de bancas de mestrado e doutorado e realizar as leituras de dissertações e teses; orientar pesquisas; dar atenção ao aluno, conforme pode ser exemplificado na fala de G17: "são atividades que demandam tempo".

Um aspecto semelhante entre os gestores, com exceção de um deles, foi a atividade docente anterior ao exercício do cargo de gestão. Ser gestor e ser professor são funções consideradas complexas e de constantes mudanças e exigências (MARRA; MELLO, 2005; KANAN; ZANELLI, 2011). Esse aspecto, no que diz respeito aos entrevistados, bem como a continuidade do exercício dessas atividades durante a gestão, conforme fala de G10 - - "é um traço característico aqui da 
Universidade que um docente assume o cargo e mantém suas atividades e mais atividades" -, está em consonância com a literatura (MARRA; MELLO, 2005; ÉSTHER, 2007; CRUZ, 2008). Portanto, além do cargo de gestão (40 horas semanais), dezessete gestores continuam envolvidos com a docência e orientação de pesquisas, atividades que já exerciam anteriormente ao cargo de gestão. Esse aspecto ocasiona o aumento de número de horas trabalhadas, a fim de que o gestor consiga exercer todas as atividades já exercidas anteriormente e mais as atividades de gestão. Alguns gestores relatam que ocorre a cobrança por produção acadêmica e científica, para o currículo lattes. Os cargos de gestão são por tempo determinado - segundo fala de G6 e G16: "eu estou secretário", "eu estou Pró-Reitor" - e, posteriormente, sobrevém o retorno às atividades de docência e pesquisa (MARRA; MELO, 2005; ÉSTHER, 2007; CRUZ, 2008).

\subsubsection{Colegas gestores}

Sob essa categoria, foram identificados os seguintes ocasionadores de estresse: em alguns casos, falta de comando; falta de decisão; falta de autoridade; divergência de ideias. Nas universidades públicas, nem sempre os gestores têm autonomia total em relação às decisões que precisam tomar em suas práticas administrativas, já que tais decisões têm de ser tomadas em conjunto com os colegiados (MARRA; MELO, 2005; ÉSTHER, 2007; CRUZ, 2008). Alguns gestores referiram-se a decisões que estão centradas na administração central da universidade.

\subsubsection{Servidores técnico-administrativos}

As situações reveladas pelos gestores, relacionadas a essa categoria, foram: técnico que não quer fazer suas atividades de trabalho; técnico que não quer cumprir oito horas diárias de trabalho; servidor antigo acomodado, sem motivação; falta de servidores (por aposentadorias - e exoneração); funcionários sem autonomia e iniciativa; pessoas acostumadas a um tipo de gestão "Eu mando você obedece"; desvio de função de servidor; servidores com necessidades - e problemas pessoais (alcoolismo, depressão); problemas entre funcionários.

\subsubsection{Assistência a um problema de saúde familiar}

As situações de ordem familiar indicadas pelos gestores como causadoras de estresse foram: pais idosos que residem sozinhos, com problemas de saúde, e querem atenção; cuidados de saúde da esposa e cuidados de saúde aos filhos. É possível observar que essa 
situação não se refere diretamente ao contexto de trabalho, mas repercute no cotidiano desses participantes (G5, G10, G15, G18, G20 e G21).

\subsubsection{Alta demanda de trabalho}

Constituem o rol de situações que marcaram essa categoria, as seguintes: assumir atividades da graduação e pós-graduação; ensino a distância; pesquisa; atividades relacionadas à gestão, como planejamentos, encaminhamentos, processos administrativos e reuniões; excesso de carga horária de trabalho; tomar decisões complexas; ministrar palestras; participar e coordenar bancas de concurso; gerir centros com muitos departamentos e cursos; encaminhar pessoalmente processos para sua resolução; atividades não previstas e que aparecem para ser resolvidas; trabalhar no improviso (falta de estabelecimento de sequências e regras); conhecer e acompanhar regimentos, legislação e estatutos, bem como as suas mudanças.

Os gestores universitários, em sua maioria, exercem vários tipos de atividades relacionadas ao exercício do cargo, além de pesquisa, docência e outras referentes ao contexto pessoal. Ser gestor em universidade é exercer um cargo com exigências e funções complexas, que contemplam tarefas diferentes e precisam ser executadas nas dimensões gerencial, administrativa, acadêmica, pedagógica, técnica e científica (ÉSTHER, 2007; KANAN, 2008; KANAN; ZANELLI, 2011). Em consonância com essas situações, ocorre a falta de conhecimentos específicos inerentes ao cargo de gestor, ou seja, não é comum as universidades investirem na capacitação profissional daqueles que exercem funções gerenciais (KANAN; ZANELLI, 2011). Em sua maioria, trata-se de professores universitários que, ao assumirem um cargo de gestão, vão assumir responsabilidades para as quais não foram preparados (MARRA; MELO, 2005; ÉSTHER, 2007; CRUZ, 2008).

\subsubsection{Vida pessoal $x$ vida profissional}

Com relação a essa categoria de fatores estressantes, foram indicados: família; cuidados com a casa; assistência a familiares idosos; não ter tempo para questões pessoais, como elaborar a progressão funcional (G6) e entrega do apartamento/móveis, por "ter que dar conta de tudo" (G19). Essa situação pode ser constatada, também, na fala de G10: "o excesso de carga horária faz com que a gente não tenha tempo para nós. Nós vivemos o nosso trabalho. 0 meu trabalho toma o tempo de lazer".

Os estressores relativos a essa categoria dizem respeito a situações complexas, caracterizadas pela tentativa de equilibrar as esferas da 
vida pessoal com as da profissional. Conforme Kanan e Zanelli (2011), os gestores têm suas vidas impactadas pelo trabalho na Direção. Esse impacto é considerado positivo em relação aos aspectos profissionais, mas é considerado negativo em relação às suas vidas particulares, em razão de que a sobrecarga de trabalho faz com que alguns gestores posterguem ou abandonem seus projetos pessoais associados a lazer, família, residência (não entrega do apartamento e móveis), questões de trabalho (progressão funcional) e também às práticas esportivas, como foi indicado por alguns gestores. A seguinte fala (G11) pode exemplificar essa situação:

Eu não tenho tempo pra mim. Eu não tenho nenhum momento só meu [...] passei na frente de um bar indo pra casa e vi três mulheres sentadas rindo e tomando cerveja. Eu nunca fiz isso. Por que eu nunca fiz isso? Porque eu nunca tenho tempo. Eu sempre tenho alguma coisa me esperando pra fazer.

Sobre lidar com a demanda de trabalho e a vida pessoal, um aspecto que chamou a atenção diz respeito às mulheres gestoras. Das sete mulheres que participaram do estudo (G1, G5, G11, G14, G19, G20 e G21), apenas uma não era casada e não tinha filhos (G19). As demais gestoras relataram as responsabilidades nos cuidados relacionados à casa e à família. G11 tem um filho com apenas três anos de idade, o que faz com que tenha de dispensar a ele cuidados constantes, como levar à escola, fazer dormir e atendê-lo quando acorda de madrugada. Ocorre, então, a dupla jornada de trabalho, exercida por essas mulheres nas esferas profissional e pessoal, que inclui cuidados com a casa, o marido e os filhos (SIQUEIRA, 2002; MENEZES, 2002), como pode ser exemplificado na fala de G11: "acham que eu sou a super-mega-mulher poderosa que consegue resolver tudo". Por outro lado, os cuidados com a casa e com os filhos não é exclusividade das mulheres gestoras. Alguns gestores dispensam também parte de seu tempo no cuidado com os filhos (G4, G7, G15 e G16). G7 cuida dos filhos gêmeos de cinco anos no período noturno para que a esposa possa trabalhar. G4, conforme acordo de separação, ficou com a responsabilidade dos cuidados com os filhos (o mais novo tem nove anos de idade) e ainda auxilia financeiramente nos cuidados do neto (bebê), conforme constatamos em sua fala: "eu sou pai e mãe [...] tenho que fazer supermercado, essas coisas todas que uma dona de casa faz" (G4).

\subsubsection{Espaço físico}


Os gestores revelaram como fatores estressantes relacionados a essa categoria: faltam salas de aula, laboratórios, sala de professores; os prédios são antigos. Essa situação foi mencionada pelos gestores pertencentes à segunda universidade pesquisada. Ao longo do tempo, houve um acelerado crescimento e expansão da universidade e, consequentemente, o aumento da oferta de cursos, do número de professores e de alunos. No entanto, mediante o crescimento da segunda universidade pesquisada, principalmente no que se refere à oferta de cursos e ao aumento de professores e alunos, sua estrutura física não acompanhou essas mudanças, o que implica consequências como o diretor ser solicitado a atender demandas individuais para não dividir sala de trabalho com outro professor e, em alguns centros, haver uma estrutura antiga, ainda de décadas passadas, com salas em más condições (chove dentro da sala e há umidade, por exemplo).

\subsubsection{Professores}

Essa categoria foi representada pelas seguintes situações estressantes, segundo os gestores: conflito entre docentes; professores resistentes à mudança; necessidade de contratação de professores substitutos e efetivos não atendida; dificuldade dos professores em ter uma relação de subordinação com o diretor; competição entre professores e entre centros de ensino; preenchimento de planilha de distribuição de carga horária de professores; professores que enviam e-mails perturbadores ou agressivos.

\subsubsection{Alunos}

Constituem situações relacionadas a essa categoria, segundo os gestores: festas no campus universitário sem autorização dos órgãos públicos e com venda de bebidas alcoólicas, produção de lixo e ocorrência de roubos; destruição do patrimônio público; denúncias à ouvidoria da universidade; problemas comportamentais (isolamento, inadaptação, situação sócioeconômica, drogas, suicídio); e alunos que chegam à Direção sem agendar.

\subsubsection{Características pessoais}

Contribuem para o estresse, as seguintes características pessoais, no entender dos entrevistados: tentar fazer o mais próximo possível da perfeição; agir de forma correta, com procedimentos corretos; ter dificuldade em reconhecer seu limite. Os gestores procuram executar suas atividades com a preocupação de desempenhar de forma correta suas funções e fazer essas atividades da melhor maneira possível. 
Agir de forma correta implica desenvolver a função de gestor com base em procedimentos e critérios estabelecidos coletivamente na universidade. É perceptível a singularidade de características de cada gestor nessas universidades, na forma peculiar de cada um realizar seu trabalho, o que decorre de fatores como características pessoais, experiências, história de vida, qualificação, apoio dos pares e domínio de diferentes habilidades de variáveis presentes nas situações que gerenciam e das avaliações que eles próprios fazem dos resultados de seu trabalho (ÉSTHER, 2007; KANAN, 2008).

Conforme Kanan e Zanelli (2011), o cargo de gestão compreende tanto habilidades associadas às práticas administrativas - como planejar, executar, dividir tarefas, designar funções, lidar com conflitos, entre outros - quanto às habilidades relacionais e pessoais - como ser acessível, saber ouvir discentes e docentes, ser flexível, ter iniciativa, ser capaz de trabalhar sob pressão, ser tolerante. Ou seja, é necessário um conjunto de habilidades no exercício do cargo de gestão.

Em consonância com a fala de todos os gestores que indicam a experiência profissional durante o exercício do cargo de gestão, em muitas universidades, os dirigentes aprendem o que é gerir um curso no próprio exercício do cargo (CRUZ, 2008) e, ainda, buscam ativar as experiências de cargos anteriores.

Essas situações, de certa forma, ajudam ocupar o cargo que hoje eu ocupo. Tem situações que eu convivi com pessoas, que eu tomei decisões, que eu viajei, que eu conheci, que eu palestrei, que eu desenvolvi experiências, que eu contatei com diversas pessoas, então acho que isso é uma experiência interessante (G17).

Ainda sobre exercer cargos de gestão, pode ser constatada, na fala de G9, a questão da falta de preparo: "eu não tive como meu planejamento inicial de vida ser gestor, mas algumas lideranças que eu adquiri pelo trabalho acabaram levando à área de gestão na Universidade [...] as pessoas não são preparadas para serem gestores". Esse aspecto pode também ser verificado nesta fala: “[...] não é nada que você aprende formalmente, é algo que você vive a vida e você vê" (G17). Os gestores relataram que o tempo de serviço e a maturidade auxiliam no exercício da função, como exemplifica G16: “[...] quando amplia a idade você tem um acúmulo de experiências, e os eventos não te assustam [...]" e também: "a experiência profissional ensina muito no dia a dia, é uma escola" (G20).

As situações estressantes foram variadas entre os participantes. É possível perceber que o que é considerado estresse para alguns 
gestores não o é para outros. Por exemplo, alguns gestores consideram a situação relacionada à "alta demanda de trabalho" como estressante; no entanto, outros relataram que esse aspecto é considerado natural ao exercício de um cargo de gestão, como pode ser exemplificado nesta fala: "eu encaro como natural, pois sempre vai haver situações de estresse" (G15). De certo modo, é possível refletir como altas exigências de trabalho fazem com que o sujeito, além de realizar o trabalho cotidiano que, muitas vezes, excede a carga horária diária, leve trabalhos para casa à noite e, muitas vezes, no final de semana; e isso passa a ser considerado natural.

Em alguns casos, a jornada estende-se para situações de férias, conforme fala de G16: "[...] eu tenho dificuldade para tirar férias [...] se eu tirar férias eu venho trabalhar". Houve também o caso de uma gestora que relatou ter dificuldade em reconhecer seu limite físico: em determinada ocasião sentiu-se mal, mas continuou a trabalhar; dois dias depois, teve uma taquicardia causada pelo excesso de exigência sobre a musculatura peitoral. Outro gestor estava diagnosticado com depressão, não tirou atestado médico e continuou a trabalhar, sem sequer comentar com alguém sobre sua situação de saúde.

Vale considerar que, para alguns gestores, não é a alta demanda de trabalho que estressa, mas sim outros são os aspectos estressantes vivenciados no cotidiano: espaço físico, processos burocráticos e lidar com pessoas. Relata G11: "não é a quantidade de compromissos que um gestor tem; é pela forma como é estruturada toda a instituição administrativamente [...]. Todo fundo de estresse de um gestor passa pela estrutura organizativa da instituição".

É possível perceber também que todos os participantes já exerceram anteriormente cargos de gestão, o que significa que já conheciam o cotidiano de trabalho de um gestor e aceitaram novos desafios ao assumir essa função novamente. Todos relataram gostar do exercício desses cargos, até porque, no contexto público universitário, podem renunciar à gestão e retornar às atividades docentes. Ficou evidente a satisfação em ser dirigente nos relatos sobre suas trajetórias profissionais e sobre as contribuições de seu trabalho à Universidade - como implantação de programas de Pós-Graduação, novas disciplinas e construção de laboratórios em muitos anos de atuação no contexto universitário. G14, por exemplo, sentiu-se mal em determinada ocasião e foi atendida por uma ex-aluna, que questionou: "Professora, o que você está fazendo aqui? Você continua exagerada nas suas aulas que você ensina tão bem pra gente? Poxa, nunca esqueci disso. Isso é gratificante".

Mas foi também perceptível em alguns gestores a interferência do estresse negativo repercutindo sobre sua saúde, com episódios de taquicardia, gastrite, bruxismo, hemorroida e nevralgia. Além do pouco tempo disponível para lazer e prática de atividades físicas, 
constata-se um contexto de muito trabalho, como pode ser verificado na fala de G17:“[...] é um cargo que você é demandado continuamente e constantemente" e na existência das situações estressantes relatadas que demandam ainda mais tempo dos gestores: "as pessoas dizem 'a não estão discutindo projetos mais inovadores' 'mas como, nós fazemos isso também', mas a gente precisa dar conta de tantas minúcias [...] se preocupar com o detalhe de tudo" (G11).

É possível perceber semelhanças entre as situações estressantes indicadas pelos gestores pertencentes às duas Universidades. $O$ fato de serem elas públicas pode ter contribuído para essas semelhanças, entre as quais constata-se o exercício anterior de outros cargos de gestão e a indicação de situações estressantes como: lidar com pessoas, processos burocráticos, atividades de graduação e pósgraduação, colegas gestores, servidores técnico-administrativos, alta demanda de trabalho e vida pessoal versus vida profissional. $\mathrm{Na}$ segunda universidade pesquisada, aspectos novos foram citados, relacionados à assistência a problema de saúde familiar, espaço físico, alunos e professores.

Os gestores, de ambas as universidades têm formação e atuação voltadas a diferentes áreas do conhecimento, o que permite verificar que, mesmo considerando as particularidades de cada curso ou área, há aspectos em comum citados como estressantes pelos dirigentes universitários.

\section{Considerações finais}

Os Gestores universitários estão inseridos em um contexto de constantes mudanças econômicas, sociais e tecnológicas, com exigências diárias de trabalho que repercutem em diferentes situações estressantes vivenciadas em seu cotidiano. Todos os Gestores, com formação e atuação voltadas a diferentes áreas do conhecimento, indicaram vivenciar várias situações estressantes no exercício do cargo, condição que se revela uma condição inerente à vida humana.

Os objetivos do estudo foram alcançados no sentido de conhecer as variadas situações estressantes vivenciadas por dirigentes universitários. As características das situações estressantes são variadas e podem ser analisadas em diferentes âmbitos. Desse modo, é possível analisar que lidar com pessoas, colegas gestores e servidores técnico-administrativos constitui categorias relacionadas ao âmbito do grupo. Alta demanda de trabalho e atividades da graduação e pós-graduação são categorias relacionadas ao âmbito da função. Lidar com processos burocráticos e de outros setores referese ao âmbito da organização. Prestar assistência a um problema de 
saúde familiar constitui uma categoria relacionada ao ambiente externo, que também está relacionado aos diferentes eventos da vida pessoal e profissional que necessitam ser equilibrados no cotidiano. Esses âmbitos permitem analisar a complexidade do fenômeno estresse e chegar ao entendimento de que ele não pode ser visto somente na perspectiva individual.

Diante desse contexto, a atuação nas universidades requer gestores com habilidades para lidar com diferentes situações de estresse. Permite também refletir sobre a importância de as organizações de trabalho, especialmente as universitárias, adotarem intervenções contínuas e implantarem programas de prevenção e gerenciamento do estresse, a fim de melhorar as condições de trabalho nesses contextos, ao considerar aspectos gerais da atuação, ou seja, levar em consideração os aspectos estressantes, indicados pelos gestores, e as mudanças nesses procedimentos. É necessário, também, analisar as condições organizacionais reveladas como mais estressoras, ou seja, aspectos que merecem maior atenção dos dirigentes, e pensar alternativas de redução do estresse. O gestor exerce papel fundamental nesse processo e é sua responsabilidade verificar ações que são viáveis para promover mudanças, criar oportunidades e ambientes mais saudáveis e positivos, e adotar mudanças na natureza intrínseca do trabalho, nas suas condições, na sua organização e no contexto organizacional mais amplo.

O estudo permitiu constatar como desdobramento futuro da pesquisa a importância de investir em capacitações contínuas para os profissionais que exercem funções gerenciais. Também, a ocorrência das situações estressantes faz refletir sobre a utilização de estratégias de enfrentamento adequadas, tanto em âmbito individual como organizacional. Daí a importância de preparar as pessoas para o enfrentamento do estresse e de criar oportunidades, ou seja, o reconhecimento por parte das pessoas de que há possibilidades de prevenir e reduzir o estresse.

Em relação às limitações do estudo, é possível considerar a não participação de todos os gestores universitários previamente contatados, três dos quais não se dispuseram a participar. Além disso, a variável tempo também foi limitante, ou seja, o pouco tempo disponível dos que concordaram em participar da pesquisa pode ter sido um fator que dificultou a coleta de dados, já que os gestores puderam permanecer menos tempo do que o ideal para tanto.

\section{Referências}

ASSMAR, E. M. L.; FERREIRA, M. C. Da injustiça organizacional ao estresse e ao esgotamento profissional. In: TAMAYO, A. (Org.). 
Estresse e cultura organizacional. São Paulo: Casa do Psicólogo, 2008. p. 281-328.

BALASSIANO, M.; TAVARES, E.; PIMENTA, R. da C. Estresse ocupacional na administração pública brasileira: quais os fatores impactantes? Revista de Administração Pública, Rio de Janeiro, v. 45, n. 3, p. 751-774, 2011.

BENEVIDES-PEREIRA, A. M. T.; DAVID, C. M.; BLASCO, R. B. 0 estresse no trabalho de profissionais em cargos gerenciais. In: Anais II Congresso Internacional de Psicologia e VII Semana de Psicologia da Universidade Estadual de Maringá, 2005.

$C R U Z, R$. C. Tipos de atividades que constituem as rotinas do trabalho de Diretores de cursos de Graduação de uma Universidade e aprendizagens para o exercício da função. 2008. 233f. Tese (Doutorado em Psicologia) - Programa de PósGraduação em Psicologia, Universidade Federal de Santa Catarina, Florianópolis, 2008.

ÉSTHER, A. B. A construção da identidade gerencial dos Gestores da alta administração das universidades federais de Minas Gerais. 2007. 276f. Tese (Doutorado em Administração) Programa de Pós-Graduação em Administração, Universidade Federal de Minas Gerais, Belo Horizonte, 2007.

FERREIRA, M. C.; ASSMAR, E. M. L. Fontes ambientais de estresse ocupacional e burnout: tendências tradicionais e recentes de investigação. In: TAMAYO, A. (Org.). Estresse e cultura organizacional. São Paulo: Casa do Psicólogo, 2008. p. 21-73.

KANAN, L. A. Características do processo de vinculação de Coordenadores de curso com o trabalho e com a universidade. 2008. 312f. Tese (Doutorado em Psicologia) - Programa de PósGraduação em Psicologia, Universidade Federal de Santa Catarina, Florianópolis, 2008.

KANAN, L.A; ZANELLI, J. C. Envolvimento de docentes-Gestores com o trabalho no contexto universitário. Psicologia \& Sociedade, Florianópolis, v. 23, n. 1, p. 56-65, 2011.

LIPP, M. E.N.; TANGANELLI, M. S. Stress e qualidade de vida em magistrados da Justiça do Trabalho: diferenças entre homens e mulheres. Psicologia: Reflexão e Crítica, Porto Alegre, v. 15, n. 3, p. 537-548, 2002.

LIPP, M. E. N. Stress no trabalho: implicações para a pessoa e para a empresa. In: NUNES, F.S. (Org.). Pedagogia institucional. Rio de Janeiro: Zit, 2005. p. 214-236.

MARRA, A. V.; MELO, M. C. O. L. A prática social de gerentes universitários em uma instituição pública. Revista de Administração Contemporânea, Curitiba, v. 9, n. 3, p. 9-31, jul./set., 2005.

MENEZES, M. I. C. B. B. Mulher, poder e subjetividade. Revista Malestar e subjetividade, Fortaleza, v. 2, n. 2, p. 59-85, set. 2002. 
MORALES, M.G.G. Estrés laboral, afrontamiento y sus consecuencias: el papel del gênero.2006. 281f. Tesis (Doutorado em Psicologia) - Facultat de Psicologia, Universitat de València, València, 2006.

PAZ, M. das G. T. Configurações de poder e estresse nas Organizações. In: TAMAYO, A. (Org.). Estresse e cultura organizacional. São Paulo: Casa do Psicólogo, 2008, p. 229-279. SADIR, M. A.; LIPP, M. E. N. As fontes de stress no trabalho. Revista de Psicologia da I MED, Passo Fundo, v. 1, n. 1, p. 114-126, 2009. SELYE, H. Stress: a tensão da vida. São Paulo: McGraw, 1959. SIQUEIRA, M. J. T. Sobre o trabalho das mulheres: contribuições segundo uma analítica de gênero. Revista Psicologia: Organizações e trabalho, Florianópolis, v. 2, n. 1, p. 11-30, jan./jun. 2002.

SILVA, E. A. T.; MARTINEZ, A. Diferença em nível de stress em duas amostras: capital e interior do estado de São Paulo. Estudos de Psicologia,Campinas, v. 22, n. 1, p. 53-61, mar, 2005.

TAMAYO, M. R. Burnout: aspectos gerais e relação com o estresse no trabalho. In: TAMAYO, A. (Org.). Estresse e cultura organizacional. São Paulo: Casa do Psicólogo, 2008. p. 75-105.

VASCONCELOS, F.C. de; VASCONCELOS, I.F.G de; CRUBELLATE, J.M. Stress in organizations: between efficiency and the institutionalization of fear. BAR, Curitiba, v. 5, n. 1, art. 3, p. 37-52, jan./mar. 2008.

ZANELLI, J. C. Trabalhadores com manifestações de stress: teorias e procedimentos utilizados em centros de pesquisas e intervenções. 2007. 124f. Pós-Doutorado Sênior. Laboratório de Estudos Psicofisiológicos do Stress, Pontifícia Universidade Católica de Campinas, Campinas, 2007.

ZANELLI, J. C. (Cols.). Estresse nas organizações de trabalho: compreensão e intervenção baseadas em evidências. Porto Alegre: Artmed, 2010.

\author{
Endereço para correspondência \\ Fernanda Ax Wilhelm \\ Universidade Federal de Roraima - UFRR \\ Campus Paricarana. Centro de Educação - CEDUC. Curso de Psicologia. \\ Avenida Ene Garcez, 2413, bairro Aeroporto. CEP 69310-000, Boa Vista - RR. \\ Endereço eletrônico: fernandaax@gmail.com \\ J osé Carlos Zanelli \\ Universidade Federal de Santa Catarina. Departamento de Psicologia. \\ Campus Universitário Trindade, CEP 88040-900, Florianópolis - SC \\ Endereço eletrônico: jczanelli@terra.com.br
}

Recebido em: 04/07/2011

Reformulado em: 19/05/2012

Aceito para publicação em: 30/06/2012

Acompanhamento do processo editorial: Deise Mancebo

\title{
Notas
}


* Doutora em Psicologia pela Universidade Federal de Santa Catarina (UFSC). Docente do curso de Psicologia da Universidade Federal de Roraima - UFRR ** Doutor em Psicologia. Docente do Departamento de Psicologia da Universidade Federal de Santa Catarina (UFSC). 